\title{
Effect of placebo substitution during long-term betamethasone valerate aerosol treatment in asthmatic children
}

\author{
JANNA FREARS, SHIRLEY HODGSON, and MAX FRIEDMAN \\ From the Department of Paediatrics, Whittington Hospital, Dartmouth Park Hill, London
}

Frears, J., Hodgson, S., and Friedman, M. (1975). Archives of Disease in Childhood, 50, 387. Effect of placebo substitution during long-term betamethasone valerate aerosol treatment in asthmatic children. Ten children with severe asthma, who had been well controlled on maintenance betamethasone valerate aerosol for an average of 11 months, were given placebo aerosols without their knowledge. The period of placebo substitution was compared with one 28-day period of betamethasone valerate therapy beforehand, and two 28-day periods afterwards.

Symptoms were increased during the placebo period, and patients did not return to their previous well-controlled state until the second month after reinstitution of therapy. Changes in the means of twice-daily peak expiratory flow readings (PEFR) followed the same pattern as changes in symptoms. The exacerbation of asthma which occurred during placebo treatment was accompanied by a widening in the diurnal variation between morning and evening PEFR. In comparison with the previous period, morning PEFR fell by a greater amount than evening PEFR. Standardized running tests suggested an increase in exercise-induced bronchoconstriction and in the Exercise Lability Index when the child was receiving only placebo treatment as compared with betamethasone valerate treatment.

The trial provided further evidence of the efficacy of betamethasone valerate aerosol in the prophylactic therapy of severe childhood asthma. As 2 of these children were able to discontinue long-term therapy it is unlikely that this drug causes dependency.

Recent studies have shown the effectiveness of betamethasone valerate aerosol in the prophylactic therapy of severe childhood asthma (Frears, Wilson, and Friedman, 1973; McAllen, Kochanowski, and Shaw, 1974). These findings are comparable with those shown in children using a different inhaled steroid with high topical activity, beclomethasone dipropionate (Dickson et al., 1973; Morrow Brown and Storey, 1973).

Follow-up of children using betamethasone valerate aerosol for longer than a year (Frears and Friedman, 1974) has shown that the initial dramatic clinical improvement experienced by most patients continues over some time and is then maintained. Many parents claim that with this therapy their children have been in better health than at any time

Received 31 October 1974. since the onset of asthma. Subjective observations are supported by analysis of daily PEFR and symptom scores recorded at home. In terms of every day life, patients are no longer hampered by their symptoms, and are able to attend school regularly and participate normally in all physical activities. The social and emotional deficit which arises from chronic ill-health has in many cases disappeared.

After initial stabilization, the child's treated state often resembles a spontaneous remission, and some parents have questioned the need to continue therapy, and in some cases have discontinued it themselves with adverse effect. The influence of suggestion upon the clinical state in asthma is well known, and we were unable to determine whether the return of symptoms seen on these occasions was due to withdrawal of the drug itself, or to anxiety 
aroused by stopping a treatment which the patient had come to regard as essential. It became desirable to withdraw therapy in a controlled fashion to show whether individual children required to continue its use. We also hoped to show that this drug does not lead to dependency by discontinuing treatment in some children after a period of prolonged maintenance.

A group of children with previously severe asthma, who had been well controlled on betamethasone valerate therapy, were therefore supplied with placebo aerosols without their knowledge, and their clinical condition during this period was compared with that during active treatment.

\section{Method}

Patients. 10 patients receiving long-term betamethasone valerate treatment on a dose-scale ranging from $800 \mu \mathrm{g}$ daily to $200 \mu \mathrm{g}$ daily, were selected. These subjects, details of whom are shown in Table I, had a mean age of 9.9 years (range $7 \cdot 6-12.8 \mathrm{yr}$ ), and had used betamethasone valerate for a mean of 11 months (range 6-15 m). All were sufficiently improved in comparison with their pretreatment state to have raised the question of discontinuing prophylactic therapy, and in each case the parents' permission had been obtained to substitute a placebo aerosol at some future unspecified date. All aerosols kept at home were handed in at every outpatient attendance and replaced with new ones to facilitate placebo substitution.

Protocol. Four 28-day periods were included in the trial. During the first period (I) the children continued treatment with long-term betamethasone valerate. Placebo treatment was substituted in the second period (II), using pressurized aerosols identical in appearance and labelling to active aerosols, but containing propellants only. If the patients' clinical state deteriorated during placebo treatment or before the planned period of substitution had been completed, betamethasone valerate was reintroduced in the third period (III) at a dose of $800 \mu \mathrm{g}$ daily. We have observed that it takes several weeks to achieve maximum benefit from this therapy, so a fourth period (IV) was included in the assessment on the assumption that this would represent a return to the optimum clinical state on active therapy.

All children attending our asthma clinic are seen at short notice on request, and parents are asked to get in touch with us on any occasion when they are worried about their child's symptoms. Advice is available at all times. This service is routine and was not particularly emphasized on the occasion when a patient was given a placebo aerosol.

Assessment. Assessment was made of the resting clinical state from daily observations recorded at home, and also by provocation using standardized exercise as a form of stress.

Observations made in the home. The children kept diary cards (Connolly and Godfrey, 1970), on which were recorded daily symptoms in the form of a score ranging from 0 (no symptoms) to 13 (severe symptoms). Morning and evening peak expiratory flow rate (PEFR) was also recorded (best of 3 on each occasion), and any asthma medication used in addition to the aerosol.

Exercise tests. Exercise tests were carried out by the method of Silverman and Anderson (1972), using a 6-minute run on a treadmill. Tests were standardized to produce tachycardia of $>160$ beats/min in each child, and were carried out at the same time of day to minimize the effect of diurnal variation. Children were not asked to run if they had a resting PEFR of $<50 \%$ of the expected mean for their height (Weng and Levison, 1969), or had used asthma medication other than the trial aerosol in the preceeding 12 hours.

Using the highest and lowest values for PEFR obtained during or after exercise, the following calculations were made:

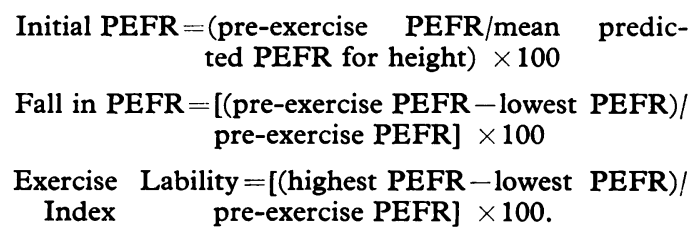

\begin{tabular}{|c|c|c|c|c|}
\hline Case no. and sex & Age at substitution (years) & Height (cm) & $\begin{array}{l}\text { Betamethasone valerate } \\
\text { maintenance }(\mathrm{m})\end{array}$ & $\begin{array}{l}\text { Duration of placebo treatment } \\
\text { (d) }\end{array}$ \\
\hline $\begin{array}{rl}1 & M \\
2 & M \\
3 & M \\
4 & M \\
5 & F \\
6 & M \\
7 & M \\
8 & M \\
9 & F \\
10 M\end{array}$ & $\begin{array}{r}7 \cdot 6 \\
12 \cdot 8 \\
8 \cdot 8 \\
8 \cdot 3 \\
10 \cdot 6 \\
12 \cdot 5 \\
8 \cdot 7 \\
10 \cdot 2 \\
9 \cdot 0 \\
10 \cdot 2\end{array}$ & $\begin{array}{l}120 \\
148 \\
119 \cdot 5 \\
128 \\
140 \\
155 \\
126 \\
144 \\
132 \cdot 5 \\
140\end{array}$ & $\begin{array}{r}6 \\
6 \\
15 \\
15 \\
14 \\
11 \\
8 \\
10 \\
14 \\
14\end{array}$ & $\begin{array}{r}5 \\
7 \\
12 \\
14 \\
19 \\
21 \\
28 \\
28 \\
40 \\
43\end{array}$ \\
\hline
\end{tabular}

TABLE I

Clinical detcils of children taking part in the trial 
The upper limit of normal ( $-2 S D)$ for the $\%$ fall in PEFR with exercise was taken as $10 \%$ (Silverman and Anderson, 1972) and as $22 \%$ for the Exercise Lability Index (König and Godfrey, 1973). All statistical comparisons in the trial were made by means of the paired ' $t$ ' test and the level of significance was taken as $\mathrm{P}<0.05$.

\section{Results}

Fig. 1 shows the individual response of one child taking part in the trial.

\section{Observations made in the home.}

Symptoms. The duration of the placebo period for each patient is given in Table I. 6 children experienced an exacerbation of symptoms on placebo therapy which became unacceptable in spite of treatment with bronchodilators and night sedation. They asked to be seen before completion of the planned substitution period of 28 days, and active treatment was reintroduced. The remaining 4 children completed the period of placebo treatment, which was extended in 2 cases. 3 of them were then returned to betamethasone valerate therapy because both we and their parents felt they had been worse without it.

Total symptom scores recorded by the 10 children in each period of the trial are shown in Table II. After placebo substitution, one child discontinued active therapy, and one ceased to keep proper records. 8 children thus had readings which could be compared in each period, and the means of these 8 are shown in Fig. 2.

Analysis of the records shows that symptom scores in the placebo period were higher than in period I $(P=0.01)$ and period IV $(P=0.01)$. The decrease in symptoms between period III and period IV is also singificant $(0.05>P>0.02)$.

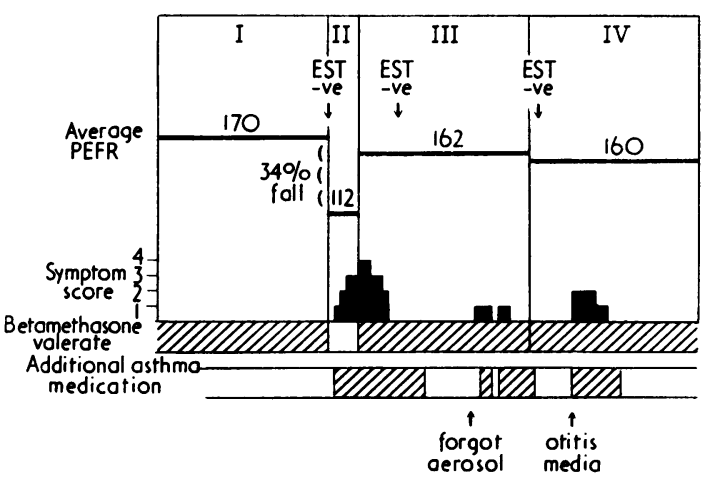

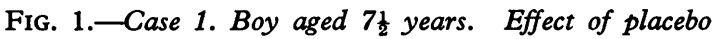
substitution during betamethasone valerate maintenance. In each of 4 trial periods are shown the average of twicedaily PEFR ( $-2 S D$ in this patient $=165)$, daily symptom score, and results of exercise stress tests (EST). This boy had had asthma since 2 years of age, preceeded by infantile eczema. 6 months' betamethasone valerate maintenance before placebo treatment period, which lasted 5 days. Exercise tests were negative $(<10 \%$ fall in PEFR) in periods of active treatment. On placebo treatment he was always too wheezy to run.

There is no difference between the symptoms recorded in periods $I$ and IV.

Changes in PEFR. 9 children used peak flow meters at home, and the averages of daily morning and evening PEFR during the trial are shown in Table III. The mean peak flow values of the 7 children whose readings could be compared throughout the trial are shown in Fig. 2.

Taking the mean of morning and evening readings in each period, all 9 children had a lower mean PEFR in period II than in period $I$, though

TABLE II

Total symptom score in 28 days

\begin{tabular}{|c|c|c|c|c|}
\hline Case no. & $\begin{array}{c}\text { Period I } \\
\text { Long-term betamethasone } \\
\text { valerate }\end{array}$ & $\begin{array}{c}\text { Period II* } \\
\text { Placebo substitution }\end{array}$ & $\begin{array}{c}\text { Period III } \\
\text { Reintroduction of } \\
\text { betamethasone valerate }\end{array}$ & $\begin{array}{c}\text { Period IV } \\
\text { Betamethasone valerate } \\
\text { maintenance }\end{array}$ \\
\hline $\begin{array}{r}1 \\
2 \\
3 \\
4 \\
5 \\
6 \\
7 \\
8 \\
9 \\
10\end{array}$ & $\begin{array}{r}0 \\
0 \\
0 \\
0 \\
0 \\
1 \\
8 \\
12 \\
33 \\
5\end{array}$ & $\begin{array}{r}50 \\
68 \\
112 \\
132 \\
21 \\
65 \\
16 \\
22 \\
13 \\
74\end{array}$ & $\begin{array}{c}21 \\
\text { No record } \\
4 \\
68 \\
3 \\
26 \\
16 \\
21 \\
29 \\
85 t\end{array}$ & $\begin{array}{r}10 \\
0 \\
0 \\
0 \\
0 \\
0 \\
10 \\
1 \\
9 \\
33+\end{array}$ \\
\hline
\end{tabular}

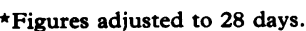

tBetamethasone valerate discontinued. 
TABLE III

Mean of daily peak expiratory flow readings

\begin{tabular}{|c|c|c|c|c|c|c|c|c|c|c|}
\hline \multirow[t]{2}{*}{ Case no. } & \multirow[t]{2}{*}{$\begin{array}{c}\text { Expected } \\
\text { PEFR - 2SD } \\
(1 / \mathrm{min})\end{array}$} & \multicolumn{2}{|c|}{$\begin{array}{c}\text { Period I } \\
\text { Long-term } \\
\text { betamethasone } \\
\text { valerate }\end{array}$} & \multicolumn{2}{|c|}{$\begin{array}{c}\text { Period II } \\
\text { Placebo } \\
\text { substitution }\end{array}$} & \multicolumn{2}{|c|}{$\begin{array}{c}\text { Period III } \\
\text { Reintroduction } \\
\text { of betamethasone } \\
\text { valerate }\end{array}$} & \multicolumn{2}{|c|}{$\begin{array}{c}\text { Period IV } \\
\text { Betamethasone } \\
\text { valerate } \\
\text { maintenance }\end{array}$} & \multirow{2}{*}{$\begin{array}{c}\% \text { Fall in PEFR } \\
\text { during period II } \\
\text { compared with } \\
\text { period I }\end{array}$} \\
\hline & & a.m. & p.m. & a.m. & p.m. & a.m. & p.m. & a.m. & p.m. & \\
\hline $\begin{array}{r}1 \\
2 \\
3 \\
4 \\
5 \\
6 \\
7 \\
8 \\
10\end{array}$ & $\begin{array}{l}165 \\
280 \\
165 \\
200 \\
245 \\
310 \\
190 \\
260 \\
245\end{array}$ & $\begin{array}{l}169 \\
223 \\
195 \\
271 \\
283 \\
472 \\
256 \\
264 \\
173\end{array}$ & $\begin{array}{l}170 \\
221 \\
203 \\
276 \\
283 \\
477 \\
282 \\
264 \\
209\end{array}$ & $\begin{array}{l}106 \\
183 \\
122 \\
182 \\
211 \\
438 \\
254 \\
258 \\
161\end{array}$ & $\begin{array}{l}118 \\
209 \\
170 \\
206 \\
238 \\
449 \\
278 \\
266 \\
195\end{array}$ & $\begin{array}{c}150 \\
\text { No } \\
205 \\
205 \\
255 \\
456 \\
249 \\
250 \\
155^{\star}\end{array}$ & $\begin{array}{l}173 \\
\text { rd } \\
221 \\
243 \\
270 \\
461 \\
260 \\
259 \\
168 \star\end{array}$ & $\begin{array}{l}147 \\
\text { No } \\
210 \\
263 \\
250 \\
484 \\
244 \\
285 \\
215^{\star}\end{array}$ & $\begin{array}{c}173 \\
\text { ord } \\
229 \\
273 \\
243 \\
488 \\
281 \\
292 \\
213^{\star}\end{array}$ & $\begin{array}{r}34 \\
12 \\
27 \\
29 \\
21 \\
7 \\
1 \\
1 \\
7\end{array}$ \\
\hline
\end{tabular}

$\star$ Betamethasone valerate discontinued.

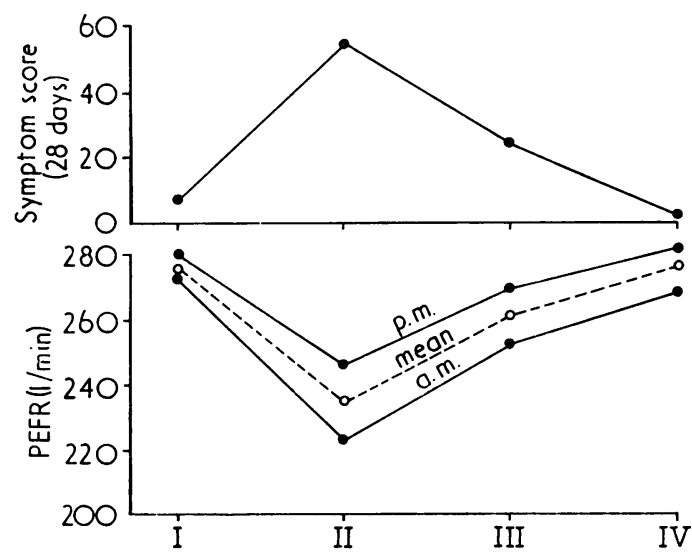

Fig. 2.-Means of total monthly symptom scores and means of daily morning and evening peak flow readings in each trial period.

in 4 children the change was small. The percentage fall in PEFR on placebo therapy ranged from $1 \%$ to $34 \%$ with an average of $15 \%(P=0 \cdot 01)$. There was a rise in PEFR after reinstitution of therapy in period IV compared with the placebo period $(P=0.01)$. There was no difference between the mean PEFR in periods I and IV.

The diurnal variation between the morning and evening PEFR in the same 7 children is also shown in Fig. 2. The variation was greater during placebo substitution than in period $I(P=0.02)$. There was also a difference between the variation in periods I and IV $(0.05>\mathrm{P}>0.02)$.

While the mean of peak flow readings dropped during placebo substitution, the morning and evening readings did not fall by the same amount.
The fall in morning readings was greater than the fall in evening readings when period II is compared with period $\mathrm{I}(0.02>\mathrm{P}>0.01)$.

Additional asthma medication. The use of asthma medication additional to the trial aerosol was observed to be greater in the placebo period than in the periods of active treatment.

Exercise stress tests. Running tests were attempted at least once a week during the placebo period, and at least once during each of the other periods. The initial PEFR of children who did running tests on both medications was $91 \%$ of their expected mean value during the placebo period, and $97 \%$ during betamethasone valerate maintenance. Silverman and Anderson (1972) have shown that variations in the initial PEFR in individual children do not affect the degree of exercise-induced bronchoconstriction. Exerciseinduced changes in PEFR in an individual patient are shown in Fig. 3. This boy did not return to betamethasone valerate therapy after period II, and the degree of exercise-induced bronchoconstriction during placebo treatment is comparable to that on no treatment in the single tests illustrated.

Fig. 4 shows the average \% fall in PEFR with exercise for each child. 4 children had a marked increase in exercise-induced bronchoconstriction on placebo treatment. 2 others, who had been able to complete exercise tests during betamethasone valerate therapy, were never well enough on placebo treatment to fulfil our criteria for being asked to run (i.e. resting PEFR $>50 \%$ of expected mean; no prior use of other asthma medication). 4 children produced similar responses to exercise 


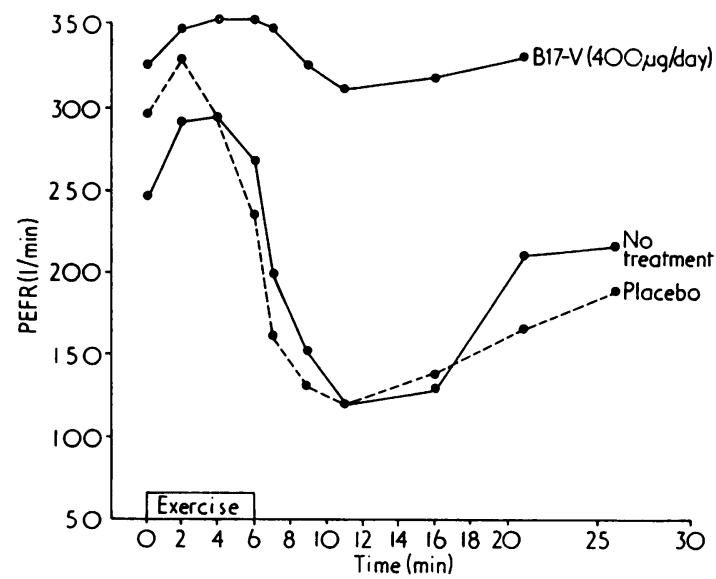

FIG. 3.-Case 10. Exercise-induced changes in PEFR with and without long-term treatment with betamethasone valerate.

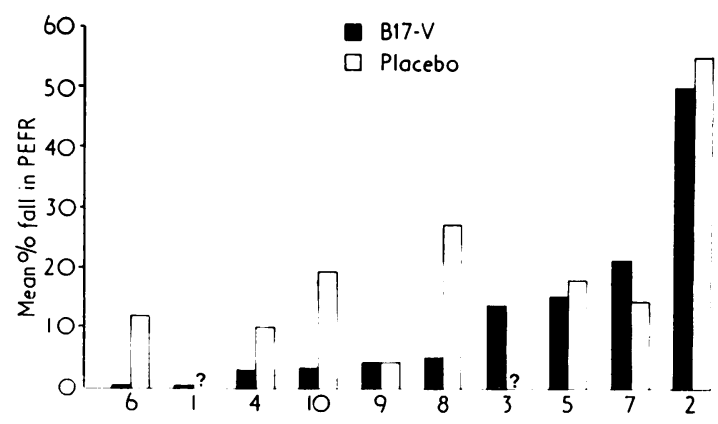

FIG. 4.-Mean percentage fall in PEFR with exercise during betamethasone valerate and placebo treatment in Cases 1-10. ?= too wheezy to run.

on both treatments. The 8 children who completed running tests on both treatments had a mean fall in PEFR on betamethasone of $13 \%$ compared with $20 \%$ on placebo therapy. Comparison of the $\%$ falls in these 8 children shows a difference $(0.05>P>0.02)$. Average value for the Exercise Lability Index of the same 8 children was 27 during betamethasone valerate maintenance and 36 during placebo therapy. Comparison of the mean results of these children shows a difference $(0.05>P>0.02)$.

\section{Discussion}

The single-blind withdrawal of therapy from asthmatic children who had been maintained on long-term betamethasone valerate led to a worsen- ing in clinical state in terms of observed symptoms and means of daily PEFR. Reinstitution of betamethasone valerate was followed by a month during which the children were not as well as they had been on long-term therapy. The second period after treatment had been started again was comparable clinically to the optimum state on long-term maintenance. There is thus a time-lag before this therapy reaches maximum effectiveness.

An attempt was made to assess whether the single-blind nature of this trial had biased the results by asking parents if they had guessed that their child was no longer on active treatment in period II. Though the return of symptoms had made a marked impression on the 6 children who requested early appointments, only one parent attributed this to withdrawal of therapy. For this reason we think it unlikely that the physician unwittingly communicated any information to the patients.

The effect of steroids upon exercise-induced asthma has not been fully evaluated. Parenteral hydrocortisone, $100 \mathrm{mg}$, administered 15 minutes before exercise was shown by McNeill et al. (1966) to have no effect on exercise-induced asthma. Heimlich, Strick, and Busser (1966) found that a 3-day course of prednisone $30 \mathrm{mg}$ daily halved the fall in PEFR after exercise. Though betamethasone valerate therapy has no immediate effect on exercise-induced bronchoconstriction, a comparison of standardized running tests suggested that its long-term use diminishes exercise-induced asthma (Hodgson, McPherson, and Friedman, 1974). The results obtained in the present trial provide additional evidence that long-term therapy with this drug decreases the amount of bronchoconstriction caused by running, and the Exercise Lability Index of individual children. The actual levels for the latter obtained on active treatment were still above the quoted normal value. We feel, however, that we have weighted the observations against showing an effect of active therapy by including in the assessment a period (III) when the children were on treatment but still not in their optimum clinical state.

We were interested in the finding that diurnal variation in PEFR became more marked during an exacerbation of symptoms, when the mean level fell, and that the fall in the morning readings was greater than the fall in evening readings. Though the difference between morning and evening PEFR was becoming less marked in the last trial period, it still varied significantly from the first trial period. Symptom scores and mean PEFR were not different during periods I and IV, and it may be that the increase in the diurnal variation which occurs in an 
exacerbation of asthma is the last thing to return to normal in a remission. Narrowing of the diurnal variation may play a part in the mechanism of long-term improvement.

Two of these 10 children, whose symptoms in the past had been severe, are now sufficiently improved to have discontinued therapy. Case 10 was dependent on long-term ACTH before successful conversion to betamethasone valerate maintenance, which continued for 14 months. He had an exacerbation of symptoms during the placebo period, but his mother found his condition tolerable and preferred to discontinue treatment. Case 8, who had been treated with betamethasone valerate for 10 months, was not markedly worse during the placebo period and was able to discontinue therapy shortly after completion of the trial. We feel that these cases provide some indication that betamethasone valerate maintenance does not lead to long-term dependency.

The results of this trial confirm our opinion that betamethasone valerate is a valuable prophylactic therapy for severe childhood asthma, and must now provide a useful alternative to ACTH or oral steroid maintenance when conventional therapy ceases to be effective.

We thank M. P. Curwen for advice on statistics; Miss Judy Maizels for assistance with running tests and preparation of data; and Glaxo Laboratories Ltd. for providing materials.
REFERENCES

Connolly, N. M., and Godfrey, S. (1970). Assessment of the child with asthma. Fournal of Asthma Research, 8, 31.

Dickson, W., Hall, C. E., Ellis, M., and Horrocks, R H. (1973). Beclomethasone dipropionate aerosal in childhood asthma. Archives of Disease in Childhood, 48, 671.

Frears, J., and Friedman, M. (1974). Experience in the use of betamethasone valerate by aerosol in asthmatic children. Postgraduate Medical fournal, 50 (Suppl. 4), 50.

Frears, J. F., Wilson, L. C., and Friedman, M. (1973). Betamethasone 17-valerate by aerosol in childhood asthma. Archives of Disease in Childhood, 48, 856.

Heimlich, E. M., Strick, L., and Busser, R. J. (1966). An exercise response test in childhood asthma. (Abst.). Fournal of Allergy, 37, 103.

Hodgson, S. V., McPherson, A., and Friedman, M. (1974). The effect of betamethasone valerate aerosol on exercise-induced asthma in children. Postgraduate Medical fournal, 50 (Suppl. 4), 69.

König. P., and Godfrey, S. (1973). Prevalence of exercise-induced bronchial lability in families of children with asthma. Archives of Disease in Childhood, 48, 513.

McAllen, M. K., Kochanowski, S. J., and Shaw, K. M. (1974). Steroid aerosols in asthma: an assessment of betamethasone valerate and a 12-month study of patients on maintenance treatment. British Medical fournal, 1, 171.

McNeill, R. S., Nairn, J. R., Millar, J. S., and Ingram, C. G. (1966). Exercise-induced asthma. Quaterly fournal of Medicine, 35, 55.

Morrow Brown, H., and Storey, G. (1973). Beclomethasone dipropionate steroid aerosol in treatment of perennial allergic asthma in children. British Medical fournal, 3, 161.

Silverman, M., and Anderson, S. D. (1972). Standardization of exercise tests in asthmatic children. Archives of Disease in Childhood, 47, 882 .

Weng, T.-R., and Levison, H. (1969). Standards of pulmonary function in children. American Review of Respiratory Diseases, $99,879$.

Correspondence to Dr. M. Friedman, Whittington Hospital, Highgate Wing, Dartmouth Park Hill, London N19 5NF. 